\title{
Fragmentos e aporias da paixão em pesquisa: do amor latente ao desejo potente
}

\author{
Carolina Ramos Nunes (Ceart/UDESC) \\ Elaine Schmidlin (Ceart/UDESC)
}

\begin{abstract}
Resumo
Este artigo trata de articulações entre a paixão cega e o amor diante de um percurso de pesquisa em quatro instituições culturais, a partir do conceito de cartografia como abordagem metodológica. A escrita é tramada na busca pelo problema da pesquisa, em forma de fragmentos e aporias, que relatam o mergulho na experiência, agenciando pesquisador e objeto de pesquisa em um mesmo plano de composição. Nesse desenho cartográfico, o desejo de pesquisar vincula-se a necessidade de escrever por um viés outro, criando um universo para um deleite enamorado, que afirma o discurso amoroso.
\end{abstract}

Palavras chave: pesquisa; cartografia; paixão; amor; experiência.

\section{Abstract}

Based on the concept of cartography as a methodological approach, this article deals with articulations between blind passion and love, regarding a research itinerary in four cultural institutes. The present loving writing weaves the quest for the object of research, through fragments and aporias that report a diving into the experience, and connects researcher and research object in the same composition plan. In this cartographic design, the desire to search is linked to the need of writing through another angle, creating a universe for a loving delight that states the loving speech.

\begin{abstract}
Na parte inferior do degrau, à direita, vi uma pequena esfera furta-cor, de quase intolerável fulgor. A princípio, julguei-a giratória; depois, compreendi que esse movimento era uma ilusão produzida pelos vertiginosos espetáculos que encerrava. O diâmetro do Aleph seria de dois ou três centímetros, mas o espaço cósmico estava aí, sem diminuição de tamanho. Cada coisa (o cristal do espelho, digamos) era infinitas coisas, porque eu a via claramente de todos os pontos do universo.
\end{abstract}

Jorge Luis Borges

Borges, sentado na parte inferior do degrau, vislumbra uma pequena esfera furta-cor de um intolerável fulgor. O Aleph, de tamanho diminuto, abriga o espaço cósmico em toda sua plenitude, motivo de admiração e paixão àqueles que dirigem seu olhar a ela. Então, pode-se perguntar: diante de um universo de pesquisa para um mestrado em que desejos, paixões e amores pulsam movendo o plano de pesquisa de um lado a outro, como escolher com sabedoria qual degrau de escada sentar-se para olhar as estrelas? O que fulgura na forma da estrela furta-cor?

Sobre o olhar para esse mapa constelar, percebendo sua fluidez consiste esse escrito: entre o amor e a pesquisa, a dor e a escrita, desenvolvem-se fragmentos e aporias, para que o enamoro com o problema a ser pesquisado torne-se, também, um discurso amoroso ${ }^{1}$, como diria Barthes.

$$
=58=
$$




\section{Paixão, amor, pesquisa}

Como pesquisar sem se apaixonar, ou melhor, sem ficar cego pelo amor que mordisca as bordas e transforma aos poucos o pesquisador, entre prantos e alegrias, naquilo que o consome? Desde a definição do que será pesquisado até os livros que acompanharão os capítulos no período de dois anos de um mestrado, a escolha deve ser tal qual como quem escolhe/conhece um amor: há coisas que se tem certeza do que se procura, outras só virão ao longo do tempo em um trabalho de imersão e convívio.

O desejo da escrita e da pesquisa consiste em uma paixão como aquela presente nos olhos de um apaixonado, consciente de cada diferença que pode corroer esta relação e ciente que, por mais arrebatadora que seja, toda a paixão culmina no amor e merece ser cultivada como tal: atentamente e detalhadamente. As nuances do amor, nas quais a pesquisa surge, estarão imbricadas nas páginas de uma dissertação que precisa, antes de corporificar-se, estruturarse em uma definição metodológica. Essa busca por uma definição permeia uma escolha mergulhada na paixão que irá desdobrar-se nos procedimentos da pesquisa, estruturando-se quase como narrativa em um processo que contempla:

[...] uma história, que tem páginas engraçadas, alegres,
divertidas e outras que são difíceis, pesadas e tristes.
Aprendemos com todas elas e não são lições de consumo
imediato, pelo contrário serão incorporadas na nossa vida.
No limite, nós somos o maior objeto da tese, pois enquanto
sujeitos dela vivemos um embate de forças internas e
externas que nos ensina muito sobre nós mesmos. (FREITAs,
2006, p.225).

Entre essas páginas, está ali imersa, quase grudando no fundo branco do papel, o método. Não menos importante, mas fundamental, essa escolha implica uma responsabilidade com os percursos da pesquisa, bem como, com as implicações dadas no projeto que reverberam nos resultados esperados, ou não, ao fim de dois anos. Assim, a escolha pelo método da cartografia recai sobre a possibilidade de circular pela pesquisa de modo a captar os

${ }^{1}$ o discurso amoroso é hoje em dia de uma extrema solidão. Este discurso talvez seja falado por milhares de pessoas (quem sabe?), mas não é sustentado por ninguém; foi completamente abandonado pelas linguagens circunvizinhas: ou ignorado, depreciado, ironizado por elas, excluído não somente do poder, mas também de seus mecanismos (ciências, conhecimentos, artes). Quando um discurso é dessa maneira levado por sua própria força à deriva do inatual, banido de todo o espírito gregário, só lhe resta ser o lugar, por mais exíguo que seja, de uma afirmação. (BARTHES, 1998)

$$
=59=
$$

ISSN: 2447-1267 Santa Catarina, v.5, n.1, ano 3, março de 2017. 
acontecimentos nela imbricadas, em que "a diretriz cartográfica se faz por pistas que orientam o percurso da pesquisa sempre considerando os efeitos do processo do pesquisar sobre o objeto da pesquisa, o pesquisador e seus resultados" (PASSOS; BARROS, 2012, p.17)

Essa imersão na experiência da cartografia como método é um processo de pesquisa fluido, que permite um caminhar que, ao mesmo tempo, traça e acompanha os efeitos do próprio percurso investigativo, tal qual como De Martino (2003) define em seu trajeto de pesquisa: "aquoso, no qual ao inventar um barco com o intento de perseguir as nuances entre o cheio e o vazio, percorri vastas extensões líquidas e terrestres." (DE MARTINO, 2003, p.06). E será por dentro deste barco que a pesquisadora narra sua excursão: "por um território que era o próprio mapa, percebendo que a minha embarcação também fazia parte da carta geográfica, pois também havia se tornado uma ilha flutuante" (Idem, 2003, p.06). A partir da carta geográfica que flutua como uma ilha, a autora permite-se ficar a deriva sem o desejo de atracar em porto seguro, uma vez que, nessa circunstância, ela também pode fazer emergir/criar outros mapas, atravessada que é pelos encontros durante o percurso.

Nessa circunscrição flutuante, a pesquisa pretendida inserese na linha do Ensino das Artes Visuais, bem como seu projeto em desenvolvimento, porém, não se limita a ela, uma vez que é atravessada no caminho pelo processo artístico e pela arte contemporânea, entre arte e educação em instituições culturais. Significativas mudanças ocorrem desde o projeto até a intervenção no campo, mediadas pela cartografia como componente afetivo do processo e do percurso da pesquisa e não somente como doce cereja sobre um bolo de chocolate desfeito, pois, "[...] não se busca estabelecer um caminho linear para atingir um fim [...]" (KASTRUP, 2014, p. 32). O fim não é a cereja, nem o saborear o bolo, mas atentar para cada etapa desde sua confecção até o ato de confeitar.

Uma relação muito próxima ao amor a pesquisa quando Roland Barthes, citado por Araujo (2008) diz: "recortando os fragmentos, provoca uma explosão sobre a superfície do texto, deixando seus estilhaços significarem e se comunicarem." (ARAUJO, 2008, p.05). Essa explosão cria outros possíveis no universo da pesquisa, permitindo outras conexões e encontros na superfície do plano de composição de uma pesquisa, ou seja, um elo que permite aos fragmentos significarem e se diferirem na criação de outras variações em modos infinitos.

$$
=60=
$$


Nesse estilhaçar de fragmentos amorosos em que singularidades espalham-se pela superfície, encontra-se a proposta de pesquisa para este artigo sobre o amor. Movimenta a escrita a necessidade de palavras, não como condição de verdade, mas como camada, não como significação, mas como sentido. Para Deluze:

O sentido é a quarta dimensão da proposição. Os Estóicos a descobriram com o acontecimento: o sentido é o expresso da proposição, este incorporal na superfície das coisas, entidade complexa irredutível, acontecimento puro que insiste ou subsiste na proposição". (DELEUZE, 2003, p.20)

Os sentidos são expressos na superfície da cartografia, de modo a sinalizar trajetos, conexões em um método de pesquisaintervenção que apresenta um plano em que pode-se projetar e intervir, porém, pouco pode-se esperar ou mesmo criar hipóteses, considerando que "intervir, então, é fazer esse mergulho no plano implicacional em que as posições de quem conhece e do que é conhecido, de quem analisa e do que é analisado se dissolvem" (PASSOS; BARROS, 2014, p. 26).

Nessa superfície em que tudo se dissolve, espalham-se os fragmentos em uma multiplicidade quase caótica como acontecimentos propondo outros sentidos ao plano de composição desta escrita. Mas, como ocorre o acontecimento? Ou como pergunta Deleuze:

Quais são as condições de um acontecimento, para que tudo seja acontecimento? O acontecimento produz-se em um caos, em uma multiplicidade caótica, com a condição de que intervenha uma espécie de crivo. [...] o caos não existe, é uma abstração, porque é inseparável de um crivo que dele faz sair alguma coisa (algo em vez de nada). (DELEUZE, 1991, p. 132)

Em fragmentos, a escrita segue, relatando alguns desses acontecimentos ocorridos ao longo do processo, de modo a recortar o objeto da pesquisa, como em um discurso amoroso, à medida que conhecer a realidade e o amor é, também, realizar uma imersão no plano da experiência, em que objeto e sujeito se desfazem para constituírem-se, novamente, no caminho do processo, tanto da pesquisa quanto do amor.

\section{Fragmento A}

A pesquisa-intervenção, recortada neste discurso amoroso, passa a se desenrolar por um recorte-fragmento localizado no centro histórico da cidade de Florianópolis (SC), em quatro $=61=$ 
instituições culturais, sendo três delas fundações públicas (uma federal e duas estaduais) e outra de nível privado. Dessas instituições, três não possuem acervo próprio, realizando exposições temporárias com a temática arte contemporânea. Uma delas possui acervo e, também, realiza exposições temporárias articulando-o a temática contemporânea exposta em seu piso inferior.

A pesquisa nesses espaços tem como objeto a mediação cultural e vem da necessidade da pesquisadora em andarilhar por outros espaços culturais, além daquele em que atua como arte educadora. No traçado geográfico da cidade, as instituições se conectam e localizam-se muito próximas umas às outras. Como um desenho cartográfico, a pesquisa aproxima as instituições no mergulho da experiência com a mediação que se desenrola em um trabalho transversal, em que desejos e paixões pelo objeto da pesquisa aparecem e contaminam uns aos outros, como em um encontro, em que "o desejo amoroso é descoberto por intuição" (BARTHES, 1998, p. 128). Assim, o amor pela mediação presente nestes espaços, antes apenas latente, torna-se desejo potente pleno de acontecimentos, efeitos de trocas teóricas, práticas e políticas em uma produção enamorada.

Desse modo, a pesquisa parte de dentro dos átrios e ventrículos, das veias e artérias, de "todas as espécies de movimentos e de desejos" (BARTHES, 1998, p. 60) - quase como uma necessidade de olhar para o chão onde andarilha-se todos os dias atentar para as nuances além do observável à primeira vista, no espaço do trabalho de mediação - e do desejo de olhar para as outras instituições e suas práticas e proposições realizadas na mediação cultural.

\section{Fragmento B}

Marguerite Duras, em seu livro Escrever (1994), narra seus dias sozinha acompanhada apenas por seus pensamentos em uma grande casa isolada perto da praia. Um destes dias é marcado por uma morte que marca a autora de tal forma que a faz escrever sobre este acontecimento. A morte é de uma mosca. Em alusão a mosca que Duras (1994) escreve, morrendo no meio de sua cozinha, tendo apenas a escritora como carpideira, propõe-se problematizar a pesquisa como se pudéssemos viver no interior da mosca que lentamente morre, percebendo, pouco a pouco, o apagar de seus olhos, um por um $=62=$ 
apagando-se, dentro e fora, imerso nela e sendo, ao mesmo tempo, observador de sua própria morte.

A morte da mosca seria a possibilidade de perceber a partir de dentro a vida que se esvai, algo que escapa, como um momento em que, ao escavar com paixão a pesquisa, uma tensão se produz que permite - desenrolar dos fios da malha que a compõe para, então, realizar outras combinações. Assim, a pesquisa conduz-se morrendo aos poucos como todas as estrelas no céu, e ao se narrar a morte por meio de palavras, estas irão ressoar naqueles que com elas encontrarem-se. Mas por que falar da morte? O que Duras (1994) propõe ao olhar e descrever com tal atenção a morte de uma pequena mosca em sua cozinha, não é o mesmo que se faz ao dissertar sobre algo, uma vez que seu teor é carregado de paixão e desejo que, muitas vezes, pode fenecer?

Desse modo, as escolhas no percurso metodológico implicam tanto em aceites quanto em negativas, sendo a pesquisa algo vivo, pulsante, que permite atravessar o pesquisador - sem pedir autorização - no processo cartográfico, as decisões implicadas durante o percurso corroboram com todo o processo, permeando o cerne da pesquisa.

A produção do conhecimento não é um empreendimento isolado. É uma construção coletiva da comunidade cientifica, um processo continuado de busca, qual cada nova investigação se insere, complementando ou contestando contribuições anteriormente dadas ao estudo do tema. (ALVES-MAZZOTTI, 2006, p.27)

Conforme Alves-Mazzoti (2006), pesquisar seria uma construção coletiva e não um empreendimento isolado dentro de um arquivo de computador ou em meio a livros fechados sobre a escrivaninha. Nessa problematização, atenta-se para como a investigação está dentro do coletivo e, ao mesmo tempo, abre-se ao coletivo, fomentando pesquisas a partir dela, deixando pontas a serem tramadas com outras proposições. Sendo assim, nota-se na forma de escrever em De Martino (2003) e até mesmo em Alves-Mazzoti (2006), uma articulação com o objeto de pesquisa e a fundamentação teórica, propondo uma escrita com os autores de modo a interagir com suas ideias.

Nesse sentido, o ato de estar entre os autores nas leituras de textos já consiste o coletivo, em que conversar com os mesmos permeia e converge com a perspectiva da proposta desta pesquisa

$$
=63=
$$

ISSN: 2447-1267 Santa Catarina, v.5, n.1, ano 3, março de 2017. 
sobre o conceito mediação cultural. Conforme Martins (2012), a mediação não seria o ato de criar pontes, mas sim o de "ficar entre muitos". Esse entre, contudo, é mais amplo que criar um espaço de conversa. É preciso, nesse lugar, provocar a conversa confluindo a pesquisa com aqueles outros autores que já falaram de algo semelhante e com outros atores presentes no processo de pesquisa, entre outros, que atravessam tanto o plano da instituição quanto o pessoal, transformando-se, portanto, em um lugar escorregadio e flutuante.

\section{Fragmento C}

A produção intelectual é ardilosa, por ser flutuante e escorregadia. Ela oscila e tem caprichos. O que chamamos de inspiração é a capacidade de reter e ampliar, com um toque próprio e único, um flash ou um insight, uma coisinha de nada que atravessa o nosso pensamento e pode fugir. Porém boa parte dessa inspiração é fruto da nossa capacidade de concentração, de disciplina, de esforço mental e até de teimosia. Precisamos não de um dia bonito de céu azul, mas de boa dose de paciência para produzir alguma coisa interessante, para organizar os raciocínios, e transformar barro em tijolos e tijolos em casas. (FREITAS, 2006, p. $220)$.

Como capturar aquele momento, o instante mais fluido e escorregadio? Quais instrumentos inventivos o pesquisador se propõe a criar para cativar a si e ao outro na sua pesquisa? Como mediar a pesquisa equilibrando a teimosia e paciência para confeccionar de tijolos a casas?

Mediar pode ser "dividir ao meio; mear. Tratar ou discutir como mediador. Estar no meio; distar igualmente. Ser mediador ou medianeiro." (Dicionário, 2016). Ou ainda, pode ser como diz Duras: "um livro aberto é, também, a noite." (DURAS, 1994, p.30). Noite aberta de vazios infinitos de possibilidades. O vazio, repleto de cheio potencial, aparece abrindo ao real, "que não está na saída nem na chegada: ele se dispõe para a gente é no meio da travessia." (ROSA, 1988, p.52)

Mas, em que lugar está esta inspiração que moveria a atenção do céu azul para o campo de pesquisa real no centro histórico da cidade cultural? Não seria, além de muita inspiração alimentada por paixão, uma busca incessante por necessidade de escrever aquilo que rodeia o objeto de pesquisa e a si mesmo? Tal como comenta De Martino (2003), em sua dissertação, ao falar da permissão que deu a si mesma para traçar seus caminhos entre o seu 
objeto de pesquisa e a metodologia, buscando escutar o acontecimento nesse percurso?

O que se media em uma instituição cultural? Antes dessa questão podem vir outras tantas como: Como se media? Há forma correta de se mediar? Quem media e quem é mediado? Mas, antes ainda desses questionamentos, faz-se necessário pensar sobre as várias linhas que escapam da meada e que formam o mesmo novelo. Para que esse escape não se torne uma fuga do objeto pesquisado, torna-se fundamental esclarecer a metodologia e os instrumentos a serem utilizados na pesquisa, bem como seu lugar e objeto.

Em uma instituição cultural, a mediação, objeto da pesquisa, estabelece-se entre o público, o artista, a obra, além de atravessar a figura do mediador e do público em visita ao campo. Nessa articulação, é necessário considerar as variáveis em torno do espaço disponibilizado para a pesquisa até o espaço de tempo (dois anos) a ser dedicado para a mesma, que incorre sempre em ousadia e risco ao propor-se mergulhar em um projeto, uma vez que

[...] o trabalho acadêmico vai necessariamente incluir a pesquisa, a investigação, a ousadia e o risco de não apenas repetir as ideias de outros, mas também desenvolver as suas próprias e posteriormente ajudar na construção das de seus alunos. (FREITAS, 2006, p.216)

Para viabilizar a pesquisa, criou-se um percurso a ser desenvolvido entre quatro instituições separadas por duas quadras, formando o desenho da Constelação de Órion ${ }^{2}$ A constelação metafórica escolhida, órion, permite a atenção para as pontas de seu quadrilátero sem deixar de considerar a existência de outras coordenadas culturais que ocorrem neste entremeio, formando outras possibilidades de pesquisa - outros fragmentos, apresentados na sequência como aporias.

\section{Aporia A - da pedra ao devir pedra}

Como transformar uma pedra em uma nuvem, pergunto eu, seria pelo amor ou pelo desejo? Diante da pergunta, continuei andando

\footnotetext{
Constelação de Órion - a constelação possui a forma de um trapézio formado por quatro estrelas maiores: Betelgeuse, Rigel, Bellatrix e Saiph, que demarcam o agrupamento de estrelas próximas. Ainda como característica marcante possui o cinturão de Orion, ou As 3 Marias, localizadas ao centro da constelação. Para que a construção do texto fosse consonante com a constelação, definiu-se as estrelas maiores como analogia para 4 instituições pesquisadas, sem desconsiderar a existência de estrelas menores em seus entremeios - outros equipamentos culturais no centro da Cidade de Florianópolis.
}

$$
=65=
$$


após o termino de uma aula, já passava das 22 horas. O vento era forte e não havia nuvens no céu. Contudo, andava com o peso extra de algo que não me pertencia antes. Descobri-me pedra. Antes vivia margeante entre ser ou não ser pedra, mas, então, percebi que caí na profundidade interna do aniquilamento como trata Deleuze (2003): sou uma pedra. Ainda, no mesmo dia, estabeleceu-se a meta de pensar o que é ser pedra sendo, também, uma não pedra.

Ainda no dia de ontem, perguntaram-me o que seria crescer pelas bordas? ou como? não me recordo ao certo. Pedras crescem? segundo Deleuze, pelas bordas. Acho que ontem estava um tanto Alice depois de comer um bolo:

\begin{abstract}
E qual não foi sua surpresa ao descobrir que ficara do mesmo tamanho! Para dizer a verdade, isso é o que geralmente acontece quando se come um bolo; mas Alice estava tão acostumada a só esperar por coisas extraordinárias, que então lhe parecia muito tolo e tedioso que a vida continuasse de modo comum. (CARROLL, 2010, p. 21-22)
\end{abstract}

Ao fim, pedras nem boca tem para comer bolos mágicos, quiçá crescer como Alices. Esse atravessamento da descoberta pedra e desejo nuvem vão além da pesquisa desejante, mas, inicia a travessia em que linhas de força, fora do projeto de pesquisa, forçam o pensamento a pensar a pesquisa de novo.

Sendo assim, a narrativa frouxa, que navega entre a ficção e o sonho, permeia a pesquisa com seus delineamentos e objetivos demarcados como que com giz no chão e, ao passar por eles, deixa-se uma marca e fica-se com um pouco do pó branco sob os pés, mas, nada foi como era antes.

\title{
Aporia B - entre nuvens, a cidade...
}

... se espalha. Uma nuvem não sabe como se move, ou melhor o vento a move, eu não sei por que me movo e é da mesma forma como andar nessa cidade.

$\mathrm{Na}$ cidade, dentre inúmeros armários existentes em uma cidade latejante, há aqueles que não são de ferro cinza que rangem à medida que se abre a porta, como se reclamassem da sua função ou da sua existência. Há armários como de antiquários, suaves, com contornos bem delineados, feitos a mão, ou quem sabe herdeiros de grandes guardados perdidos pelo tempo, que jamais poderão retomar aquilo que viveram.

Neste escopo de armários, há sempre um destinado aos achados e perdidos. Imagina-se que, quando se entra nos achados e perdidos

$$
=66=
$$


encontra-se tudo, mas, perde-se uma infinidade de coisas, caso contrário, para que serviria os achados e perdidos se não para perder-se nele e, quem sabe, com sorte achar-se?

Imagina-se um armário guichê, um pouco menor que o restante ao seu redor, pode ser colorido, aqui não há pudores para normativas. Precisa ser constantemente averiguado, verificado, remediado e suas devidas fechaduras merecem generosas quantias de óleo. Portas grandes para caber qualquer tipo de quinquilharia, janelas para respirar caso bicho vivo seja perdido, luz interna para aqueles que por ali resolverem ficar e perderem-se numa leitura noturna e, ainda, um tapete a sua frente para manter a higiene dos calçados ao entrar-se em solo quase sagrado.

Este guichê, que agora ultrapassa sua corporeidade de armário, precisa de um funcionário atento aos detalhes de tudo aquilo e para aqueles que entram e saem dele. Anota-se e notam-se aqueles que entraram para passear, para ver se perderam algo, ou para achar aquilo que se imaginava ter perdido, ou mero desejo de tentar compreender a incompreensível sociedade que se vive.

Botinas apertadas, calças confortáveis e um senso atento compõe o funcionário. Aos poucos ele se perde entre o guichê armário e se faz um pouco parte de tudo aquilo, um tanto enrijecido como as portas, com tinta escorrendo e descascando pelas mãos e um olhar que se priva a ver pelas frestas respiradoras da fronte.

Então, como fluir a metodologia para que a pesquisa, assim como - guichê descrito acima, tenha respiros, singularidades, feitiçarias, desejos, focos, referências e um corpo vibrante?

Andarilhar pelo guichê, ainda que mentalmente, sem a expectativa do que irá encontrar naquele espaço, ou ainda mais, perder-se nele, permite premissas cartográficas.

Fala-se em cartografia e imaginam-se mapas. O funcionário, com suas botas, deve ter um mapa daquilo que guarda dentro das portas de seu receptáculo labiríntico, para que ele mesmo não se perca. Será? Como perder-se e fazer parte dos achados e perdidos, mas, como não perder-se entre os rumos que se toma, sem certezas, como a perder-se em um labirinto? Bem, vê-se a necessidade de um norte, para que o armário permaneça no mesmo lugar dentro da imensidão que o compõe, mas dentro desta delimitação, flânear é preciso, como diria Benjamin (2006).

Diante do guichê de achados e perdidos flânea-se até as nuvens, pois, a partir da pesquisa cartográfica chegou-se ao objeto de $=67=$ 
pesquisa, ao menos o recorte do mesmo, e o viés poético que une a proposição narrativa do projeto. Sendo assim, do guichê de achados e perdidos que inicia um namoro com a pesquisa e a instituição a ser pesquisada, abre-se outro plano de experiências, que permite ser adensado, ou neste caso, flutuado, até que se possa encontrar as nuvens.

\section{Do fim sem fim...}

Não obstante, ocorre a pesquisa no lugar do entre, estando em consonância com público, artista, espaço expositivo, equipe de arte educação, conceitos, bibliografia, conectando as perspectivas de modo que um roteiro seja criado sem amarras, porém tensionadas pelas partes componentes deste percurso.

Sendo esta uma afirmação/proposição a ser investigada por dois anos, ou agora só 1 ano e meio de pesquisa, desejo que a morte tanto das estrelas como de mim mesma como mosca parada no meio da cozinha, se faça potente e articulada com tudo aquilo que foi proposto e, caso não seja, que o amor fale mais alto e deixe-se andarilhar por cada percurso apaixonadamente traçado.

Diante da paixão que corrói as escrituras, restam ao pesquisador colher pequenos fragmentos-sentidos que, em separado, podem ressoar como arrogantes e ausentes de sentido, mas em conjunto, propõe corpo caóide e criador para aquele que constrói a leitura. Ampliar pequenos ensaios para grandes inspirações ou melhor aspirar que grandes ensaios tornem-se minutos de inspiração como propõe Deleuze, é tarefa árdua nos entremeios afogados pela pesquisa, mas sempre há margem próxima de onde pode-se, pouco a pouco, tatear desejos, roçar vontades e mirar outras perspectivas. 


\section{Referências}

ALVES-MAZZOTI in Lucídio; MACHADO, Ana Maria Netto (Org.). A bússola do escrever: desafios e estratégias na orientação de teses e dissertações. Florianópolis: Ed. da UFSC; São Paulo: Cortez, 2006.

ARAÚJO, Rodrigo da Costa. Semiologia Do Amor: notas para uma leitura de "Fragmentos do Discurso Amoroso", de Roland Barthes. 2008. Artigo Completo do XII Congresso Nacional de Linguística e Filologia.

Disponível em: <http://www.filologia.org.br/xiicnlf/>. Acesso em: 20 de maio de 2016 .

BARTHES, Roland. Fragmentos de um discurso amoroso. 14. ed. Rio de Janeiro: F. Alves, 1998.

BENJAMIN, Walter; BOLLE, Willi; TIEDEMANN, Rolf. Passagens. Belo Horizonte: Ed. da UFMG; São Paulo: Imprensa Oficial do Estado de São Paulo, 2006 .

BORGES, Jorge Luis. O aleph (1949). São Paulo: Companhia das Letras, 2008. $156 \mathrm{p}$.

CARROLL, Lewis. Alice: aventuras de Alice no país das maravilhas \& através do espelho e o que Alice encontrou por lá. Rio de Janeiro: J. Zahar, 2010 .

DURAS, Marguerite. Escrever. Trad. Rubens Figueiredo. Rio de Janeiro: Rocco, 1994.

DELEUZE, Gilles. Lógica do sentido. 4. ed. São Paulo: Perspectiva, 2003 .

Papirus, 1991 .

- A dobra: Leibniz e o barroco. 5. ed. Campinas (SP) :

DE MARTINO, Marlen Batista; CAMPOS, Cynthia Machado. Do vazio ao labirinto: o espaço e a arte contemporânea: uma história das sensibilidades e percepções sobre o espaço através da arte contemporânea. 2004116 p. Dissertação (Mestrado), UFSC, Centro de Filosofia e Ciências Humanas.

FREITAS in BIANCHETTI, Lucídio; MACHADO, Ana Maria Netto (Org.). A bússola do escrever: desafios e estratégias na orientação de teses e dissertações. Florianópolis: Ed. da UFSC; São Paulo: Cortez, 2006.

MARTINS, Mirian Celeste; PICOSQUE, Gisa. Mediação cultural para professores andarilhos na cultura. $2^{a}$ Edição. - São Paulo: Intermeios, 2012.

PASSOS E BARROS in PASSOS, E.; KASTRUP, V.; ESCÓSSIA, L. Pistas do método da cartografia: pesquisa-intervenção e produção de subjetividade. Porto Alegre: Sulina, 2014. PoRTuguês, Dicionário Online de (Ed.). Mediação: Significado de Mediação. 2016. Disponível em: <http://www.dicio.com.br/mediacao/>. Acesso em: 22 abr. 2016.

ROSA. Guimarães. Grande sertão: veredas. Rio de Janeiro: Ed Nova Fronteira, 1988 .

$$
=69=
$$




\section{APOTHEKE}

ESTÚDIO DE

P INT URA

\section{Carolina Ramos Nunes}

Mestranda do Programa de Pós Graduação em Artes Visuais (PPGAV - UDESC), na linha de Ensino das Artes Visuais, sob orientação da Prof. ${ }^{a}$ Dr. ${ }^{a}$ Elaine Schmidlin; Membro do Grupo de Pesquisa Entre Paisagens UDESC/CNPq; Pós-graduada em Mídias da Educação pela UAB-IFSC, 2014; Licenciada em Artes Visuais pela UDESC - CEART, 2013; Atualmente exerce a função de Arte Educadora na Fundação Cultural Badesc, localizada na cidade de Florianópolis, SC.

http://lattes.cnpq.br/5448524601348039

\section{Elaine Schmidlin}

Professora no Programa de Pós-graduação em Artes Visuais (PPGAV) e no curso de Licenciatura em Artes Visuais do Centro de Artes (CEART) da Universidade do Estado de Santa Catarina (UDESC). Doutora em Educação, linha de pesquisa Ensino e Formação de Educadores, pela Universidade Federal de Santa Catarina (UFSC), 2013; Membro do Grupo de Pesquisa Entre Paisagens UDESC/CNPq.

http://lattes.cnpq.br/9781556928615419 